\title{
BENTUK DAN TINGKAT PARTISIPASI MASYARAKAT TERHADAP BANJIR SUNGAI BUNTUNG DI KECAMATAN WARU \\ Mahfudlotur Rohmaniyah" ${ }^{1}$, Linda Dwi Rohmadiani ${ }^{2)}$ \\ ${ }^{1) 2)}$ Fakultas Teknik Sipil dan Perencanaan Universitas PGRI Adi Buana Surabaya Email: nia.ni01603@gmail.com
}

\begin{abstract}
Abstrak
Kecamatan Waru termasuk dalam kawasan rawan bencana banjir karena dilalui oleh Sungai Buntung. Sungai Buntung merupakan anak sungai dari Sungai Brantas memiliki panjang $\pm 34 \mathrm{~km}$, melewati hampir seluruh desa di Kecamatan Waru. Genangan air yang terjadi pada daerah tersebut mencapai ketinggian $0,05 \mathrm{~m}$ sampai $0,5 \mathrm{~m}$ dan berlangsung selama 1 sampai 2 hari selama musim penghujan. Tujuan dari penelitian ini adalah untuk mengidentifikasi bentuk partisipasi tiap tahapan penanggulangan dan tingkat partisipasi masyarakat dalam menanggulangi banjir Sungai Buntung. Metode penelitian yang digunakan adalah deskriptif kuantitatif dengan teknik analisis persentase dan skoring. Hasil analisis persentase menunjukkan bahwa bentuk partisipasi terbanyak pada sebelum banjir (41\%), saat banjir (58\%), dan setelah banjir (40\%) berupa tenaga. Berdasarkan analisis skoring, tingkat partisipasi masyarakat di Kecamatan Waru kategori degrees of tokenisme adalah Desa Berbek (informing), Desa Kedungrejo, Kureksari, Bungurasih, dan Medaeng (consultation), Desa Tambak Rejo dan Ngingas (placation). Kategori degrees of citizen power adalah Desa Waru dan Wedoro (partnership), dan Desa Kepuh Kiriman (delegated power).
\end{abstract}

Katakunci : Partisipasi Masyarakat, Penanggulangan Banjir, Sungai Buntung

\begin{abstract}
Waru District is included in a flood prone area because it is crossed by the Buntung River. Sungai Buntung is a tributary of the Brantas River which has a length of $\pm 34 \mathrm{~km}$, passing through almost all villages in Waru District. Puddles that occur in the area reach an altitude of $0.05 \mathrm{~m}$ to 0.5 $m$ and last for 1 to 2 days during the rainy season. The purpose of this study is to identify the form of participation in each step of the response and the level of community participation in tackling the Buntung River flood. The research method used is descriptive quantitative with percentage analysis and scoring techniques. The results of percentage analysis show that the most forms of participation were before the flood (41\%), during the flood (58\%), and after the flood (40\%) in the form of labor. Based on the scoring analysis, the level of community participation in the Waru District category of degrees of tokenism is Berbek Village (informing), Kedungrejo Village, Kureksari, Bungurasih, and Medaeng (consultation), Tambak Rejo Village and Ngingas (placation). The degrees of citizen power categories are Waru and Wedoro Villages (partnership), and Kepuh Kiriman Village (delegated power).
\end{abstract}

Keywords: Buntung River, Community Participation, Flood Mitigation

\section{PENDAHULUAN}

Banjir adalah luapan air yang melebihi kapasitas penampang atau melewati batas elevasi rencana sungai akibat curah hujan yang tinggi. Banjir merupakan salah satu bencana alam yang mempunyai dampak besar bagi kelangsungan hidup manusia. Banjir dapat menyebabkan kerusakan parah, khususnya pada daerah yang padat penduduk yang berada di bantaran sungai atau daerah-daerah yang terkena banjir periodik (Riska \& Yuliastuti, 2013). Kecamatan Waru merupakan bagian dari wilayah Kabupaten Sidoarjo, yang berfungsi sebagai kawasan permukiman perkotaan dengan tingkat orde kota-1, dan merupakan kawasan perkembangan ekonomi wilayah. Berdasarkan Peraturan Daerah No 6 Tahun 2009 tentang Rencana Tata Ruang Wilayah Kabupaten Sidoarjo tahun 20102030, Kecamatan Waru termasuk dalam kawasan rawan bencana banjir karena dilalui oleh Sungai Buntung (Pasal 54). Sungai Buntung merupakan anak sungai dari Sungai Brantas bagian hulu dari Kecamatan Krian 
kemudian mengalir ke Kecamatan Taman dan Kecamatan Waru sampai muara (Selat Madura). Sungai buntung memiliki panjang \pm $34 \mathrm{~km}$, melewati hampir seluruh desa di Kecamatan Waru yaitu Desa Bungurasih, Kedungrejo, Waru, Medaeng, Janti, Ngingas, Kureksari, Berbek, Wedoro, Tambak Oso, Kepuh Kiriman, Tambak Rejo, Tambak Sawah, dan Tambak Sumur (Gambar 1). Fungsi dari Sungai Buntung di Kecamatan Waru merupakan drainase primer, akan tetapi banyak warga yang membuang sampah di Sungai Buntung dikarenakan kurang tersedianya Tempat Pengolahan Sampah di Kecamatan Waru (Bappeda Kabupaten Sidoarjo, 2016).

Wesli pada Tahun 2011, melakukan penelitian mengenai partsipasi masyarakat dalam pengendalian banjir di Kabupaten Aceh Utara yang menunjukkan bahwa partsipasi masyaraket masih rendah dan kurangnya peluang yang diberikan pemerintah pada keikutsertaan masyarakat (Wesli, 2011). Penelitian mengenai tingkat partisipasi masyarakat dalam mitigasi bencana banjir di Kelurahan Sangkrah, Kecamatan Pasar Kliwon Surakarta Tahun 2013 menghasilkan bahwa tingkat partisipasi masyarakat tinggi bagi masyarakat yang tinggal di dekat bantaran sungai, sedangkan yang tinggal jauh dari bantaran sungai tingkat partisipasinya sedang (Utami, 2013). Penelitian tentang sikap sosial masyarakat dalam penanggulangan korban banjir di Provinsi Lampung dilaksanakan pada tahun 2016, menunjukkan bahwa pengetahuan dan pemahaman masyarakat tentang bencana alam banjir Provinsi Lampung sudah tinggi sehingga upaya pencegahan dan penanggulangan bencana banjir yang dilaksanakan oleh petugas instansi terkait lebih efektif (Widayanti, 2016). Penelitian mengenai faktor-faktor dan partisipasi masyarakat dalam penanggulangan masalah banjir di kelurahan Sempaja Barat Kecamatan Samarinda Utara dilaksanakan pada Tahun 2017 yang menyimpulkan bahwa partisipasi masyarakat dalam penanggulangan masalah banjir sangat rendah (Noorwandy, 2017). Partisipasi masyarakat dalam penanggulangan bencana di Kecamatan Jatinangor bertujuan untuk melihat bentuk partisipasi dengan menggunakan metode analisis interpretasi data primer dan data sekunder (Umeidini et al, 2019).

Berdasarkan permasalahan tersebut, maka dilakukan penelitian tentang bentuk dan tingkat partisipasi masyarakat terhadap penanggulangan banjir bantaran Sungai Buntung di Kecamatan Waru yaitu Desa Bungurasih, Desa Kedungrejo, Desa Waru, Desa Medaeng, Desa Ngingas, Desa Kureksari, Desa Berbek, Desa Wedoro, Desa Kepuh Kiriman dan Desa Tambak Rejo. Partisipasi masyarakat adalah keikutsertaan masyarakat dalam proses pengidentifikasian masalah dan potensi yang ada di masyarakat, pemilihan dan pengambilan keputusan tentang alternatif solusi untuk menangani masalah, pelaksanaan upaya mengatasi masa lah, dan keterlibatan masyarakat dalam proses mengevaluasi perubahan yang terjadi (Isbandi, 2007).

\section{METODOLOGI PENELITIAN}

A. Metode Pengumpulan Data

Sumber data dalam penelitian ini diperoleh dari data primer, yaitu data yang diperoleh dari penyebaran kuisioner, wawancara, dan observasi. Data sekunder diperoleh dari instansi terkait yaitu BPS Kabupaten Sidoarjo, Bappeda, dan Kantor Kecamatan Waru.

B. Metode Analisa

Metode analisis yang digunakan dalam mencapai tujuan terdiri atas dua tahapan yaitu

1) Mengidentifikasi bentuk partisipasi pada tiap tahapan penanggulangan bencana

Analisis ini menggunakan teknik analisa deskriptif persentase. Langkah-langkah teknik analisis deskriptif persentase menurut Ali (2010) yaitu:
a. Menghitung nilai responden dan masing-masing aspek atau sub variabel.
b. Merekap nilai.
c. Menghitung nilai rata-rata.
d. Menghitung persentase dengan rumus:

Keterangan:

$$
\mathrm{DP}=\frac{\mathrm{n}}{\mathrm{N}} \times 100 \%
$$

$$
\begin{array}{ll}
D P & =\text { Deskriptif Persentase }(\%) \\
n & =\text { Skor empirik (Skor yang diperoleh) } \\
N & =\text { Skor maksimal item pertanyaan }
\end{array}
$$

e. Cara menentukan tingkat kriteria adalah sebagai berikut: (Tabel 1)

$$
\text { Persentase Maksimal }=\frac{\text { skor maksimal }}{\text { skor } \text { maksimal }} \times 100 \%
$$




$$
\text { Persentase Minimal }=\frac{\text { skor mminimal }}{\text { skor maksimal }} \times 100 \%
$$

Tabel 1 Kriteria Penilaian Bentuk Partisipasi Masyarakat di Kecamatan Waru

\begin{tabular}{|c|c|c|c|}
\hline Tahapan & Bentuk Partisipasi & Persentase & Kriteria \\
\hline \multirow{12}{*}{$\begin{array}{l}\text { a. Sebelum tejadi } \\
\text { banjir (Mitigasi ) } \\
\text { b. Saat terjadi banjir } \\
\text { (Tanggap darurat) } \\
\text { c. Setelah terjadi banjir } \\
\text { (Pemulihan) }\end{array}$} & \multirow{4}{*}{ Tenaga } & $75 \%-100 \%$ & Sangat Tinggi \\
\hline & & $50 \%-75 \%$ & Tinggi \\
\hline & & $25 \%-50 \%$ & Rendah \\
\hline & & $1 \%-25 \%$ & Sangat Rendah \\
\hline & \multirow{4}{*}{ Uang } & $75 \%-100 \%$ & Sangat Tinggi \\
\hline & & $50 \%-75 \%$ & Tinggi \\
\hline & & $25 \%-50 \%$ & Rendah \\
\hline & & $1 \%-25 \%$ & Sangat Rendah \\
\hline & \multirow{4}{*}{ Buah Pikir } & $75 \%-100 \%$ & Sangat Tinggi \\
\hline & & $50 \%-75 \%$ & Tinggi \\
\hline & & $25 \%-50 \%$ & Rendah \\
\hline & & $1 \%-25 \%$ & Sangat Rendah \\
\hline
\end{tabular}

Sumber : diolah Tahun 2018

2) Mengidentifikasi tingkat partisipasi masyarakat menurut tangga partisipasi Armstein

Analisis ini menggunakan teknik analisa skoring. Analisa skoring adalah analisis yang menggunakan angka dengan batasan nilai pada skoring yang sudah ditentukan terlebih dahulu (Iswara et al, 2017) . Analisis skoring yang dilakukan terdapat tiga langkah. Langkah pertama adalah menentukan kategorisasi tingkat partisipasi masyarakat seperti pada Tabel 2 .

Tabel 2 Indikator Tingkat Partisipasi Masyarakat

\begin{tabular}{|c|c|c|c|}
\hline $\begin{array}{c}\text { Tahapan } \\
\text { Penanggulangan } \\
\text { Bencana }\end{array}$ & Indikator & Keterangan & Skor \\
\hline \multirow{16}{*}{$\begin{array}{l}\text { Sebelum Terjadi } \\
\text { Banjir (Mitigasi } \\
\text { Bencana Banjir) }\end{array}$} & \multirow{3}{*}{$\begin{array}{l}\text { Membuat pertemuan } \\
\text { untuk membahas } \\
\text { pengalaman banjir }\end{array}$} & $\begin{array}{l}\text { Adanya kalender musim sebagai landasan pelaksanaan } \\
\text { waktu kegiatan dapat dilakukan di dalam pertemuan ini. }\end{array}$ & 5 \\
\hline & & Pertemuan secara teratur di tingkat RW dan kelurahan & 3 \\
\hline & & $\begin{array}{l}\text { Pernah ada pertemuan dengan warga tingkat } \mathrm{RW} \text { atau } \\
\text { Kelurahan }\end{array}$ & 1 \\
\hline & \multirow{3}{*}{$\begin{array}{l}\text { Pemberdayaan } \\
\text { masyarakat }\end{array}$} & $\begin{array}{l}\text { Kontribusi dari masyarakat yang bekerja sama dengan } \\
\text { lembaga/ organisasi dapat berupa tenaga kerja, waktu, ide, } \\
\text { dan lain-lain. }\end{array}$ & 5 \\
\hline & & Diprakarsai dari swadaya masyarakat sendiri & 3 \\
\hline & & Diprakarsai dari lembaga/ organisasi masyarakat & 1 \\
\hline & \multirow{3}{*}{$\begin{array}{l}\text { Meningkatkan } \\
\text { kesadaran dan } \\
\text { pengertian masyarakat } \\
\text { tentang penyebab banjir } \\
\text { dan dampaknya }\end{array}$} & $\begin{array}{l}\text { Tiap warga rutin membersihkan selokan, got dan sungai dari } \\
\text { sampah dan pasir }\end{array}$ & 5 \\
\hline & & $\begin{array}{l}\text { Warga kerja bakt saat mendekati banjir saja atau sudah } \\
\text { terkena banjir }\end{array}$ & 3 \\
\hline & & Kurangnya kesadaran warga untuk kerja bakti & 1 \\
\hline & \multirow{3}{*}{$\begin{array}{l}\text { Promosi keterlibatan } \\
\text { masyarakat dan } \\
\text { pertolongan diri sendiri }\end{array}$} & $\begin{array}{l}\text { Warga berinovasi untuk menanggulangi banjir di daerahnya } \\
\text { (membuat bendungan, dsb) }\end{array}$ & 5 \\
\hline & & $\begin{array}{l}\text { Sekurang-kurangnya satu bulan sebelum musim hujan, } \\
\text { anggota masyarakat diminta untuk berperan aktif dalam } \\
\text { kegiatan-kegiatan pencegahan banjir }\end{array}$ & 3 \\
\hline & & Warga pasif akan terjadinya banjir & 1 \\
\hline & \multirow{3}{*}{$\begin{array}{l}\text { Membentuk dan } \\
\text { memperkenalkan } \\
\text { sistem peringatan dini }\end{array}$} & $\begin{array}{l}\text { Memiliki sistem peringatan dini dapat berupa pengeras } \\
\text { suara dari mesjid, kentongan, memukul tiang listrik atau alat } \\
\text { lainnya. }\end{array}$ & 5 \\
\hline & & Memiliki wacana untuk membuat simulasi dini & 3 \\
\hline & & Tidak ada system peringatan dini di daerahnya. & 1 \\
\hline & Membangun & Rutin mengadakan pelatihan untuk masyarakat untuk & 5 \\
\hline
\end{tabular}


Mahfudlotur Rohmaniyah dan Linda Dwi Rohmadiani : Bentuk dan Tingkat Partisipasi Masyarakat terhadap Banjir Sungai Buntung di Kecamatan Waru

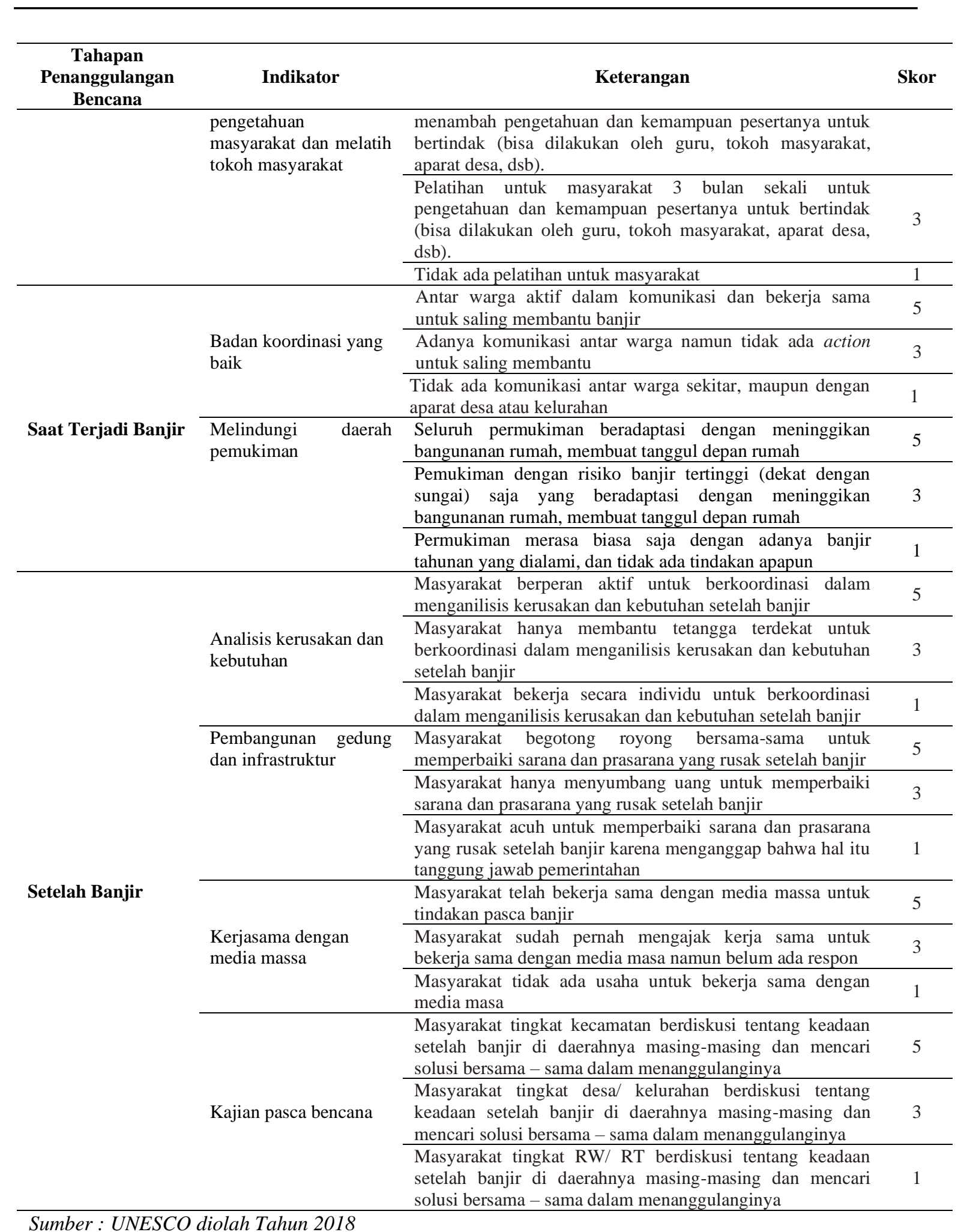

Langkah kedua adalah menghitung jumlah skor tingkat partisipasi masyarakat sesuai dengan langkah pertama.

Keterangan :

$$
I=\frac{\sum B}{\sum N}
$$

I = Tingkat Partisipasi 
$\mathrm{B}=$ Jumlah Skor

$\mathrm{N}$ = Jumlah skor maksimal

Langkah ketiga adalah mengkasifikasikan tingkat partisipasi masyarakat sesuai hasil perhitungan pada langkah kedua seperti Tabel 3.

Tabel 3 Klasifikasi Skala Partisipasi Masyarakat

\begin{tabular}{|c|c|c|c|}
\hline No. & Tingkatan & Range & Tingkatan \\
\hline 1 & Citizen control (Pengawasan Masyarakat) & $87,5-100 \%$ & \multirow{3}{*}{$\begin{array}{l}\text { Tingkat kekuasaan } \\
\text { masyarakat (Partisipasi } \\
\text { Tinggi) }\end{array}$} \\
\hline 2 & Delegated power (Pendelegasian Kekuasaan) & $75-87,5 \%$ & \\
\hline 3 & Partnership (Kemitraan) & $62,5-75 \%$ & \\
\hline 4 & Placation (Peredaman) & $50-62,5 \%$ & \multirow{3}{*}{$\begin{array}{l}\text { Tingkat Tokenisme } \\
\text { (Partisipasi Sedang) }\end{array}$} \\
\hline 5 & Consultasion (Konsultasi) & $37,5-50 \%$ & \\
\hline 6 & Informing (Menyampaikan Informasi) & $25-37,5 \%$ & \\
\hline 7 & Theraphy (Terapi) & $12,6-25 \%$ & \multirow{2}{*}{$\begin{array}{l}\text { Non partisipasi } \\
\text { (Partisipasi Rendah) }\end{array}$} \\
\hline 8 & Manipulation (Manipulasi) & $0-12,5 \%$ & \\
\hline
\end{tabular}

\section{HASIL DAN PEMBAHASAN}

A. Identifikasi Bentuk Partisipasi Pada Tiap Tahapan Penanggulangan Bencana

Bentuk-bentuk partisipasi masyarakat menurut Holil (dalam Deviyanti, 2013) yaitu dalam suatu program pembangunan, yaitu partisipasi uang, partisipasi harta benda, partisipasi tenaga, partisipasi keterampilan, partisipasi buah pikiran, partisipasi sosial, partisipasi dalam proses pengambilan keputusan, dan partisipasi representatif. Berdasarkan hasil analisis (Gambar 1) bentuk partisipasi pada tahapan sebelum banjir tertinggi berupa tenaga sebesar $41 \%, 25 \%$ berupa uang, $10 \%$ berupa buah piker atau pendapat dan $24 \%$ warga tidak berpartisipasi. Bentuk partisipasi berupa tenaga pada masingmasing desa cukup beragam. Masyakat Desa Medaeng, Desa Waru, Desa Bungurasih, dan Desa Kedungrejo secara bergotong royong membersihkan sungai setiap 6 bulan sekali yang dibantu pula dari pihak Dinas PU Pengairan Provinsi Jawa Timur serta turut menertibkan bangunan-bangunan liar di Sempadan Sungai Buntung.

Masyarakat Desa Kureksari dan Desa Ngingas bekerja sama untuk membersihkan sampah di Sungai Buntung menggunakan perahu kecil dan tongkat. Masyakat Desa Wedoro dan Desa Kepuh Kiriman setiap 3 bulan sekali bekerja sama membersihkan Sungai Buntung dari sampah dan juga tanaman-tanaman air (eceng gondok). Desa Kepuh Kiriman memiliki organisasi yang bernama "Polisi Sungai" untuk berpatroli menjaga sungai dari warga yang membuang sampah ke sungai. Desa Berbek satu bulan sebelum banjir mengadakan kerja bakti untuk membersihkan lingkungan sekitar.

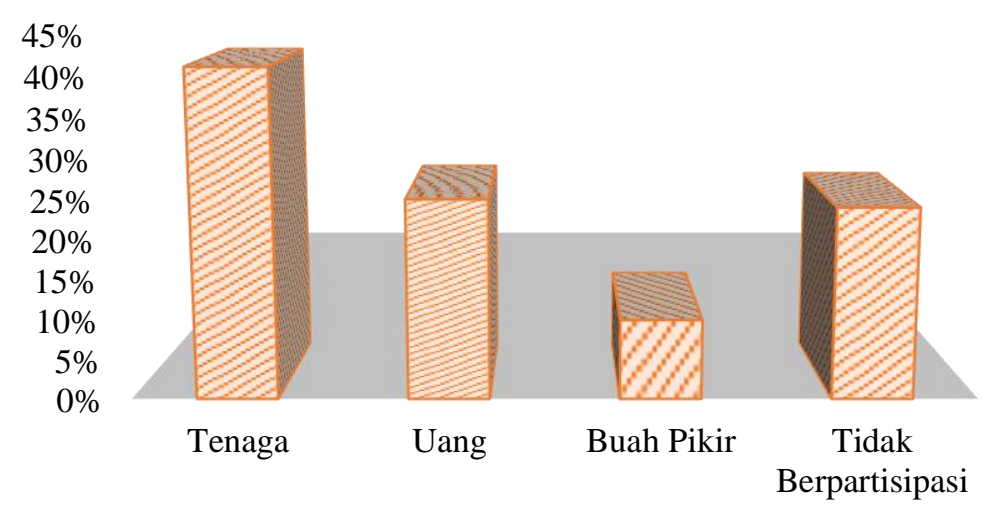

Gambar 1 Diagram Bentuk Partisipasi Masyarakat Sebelum Terjadi Banjir Tahun 2018

Saat terjadi banjir, 58\% warga berpartisipasi berupa tenaga, $21 \%$ berupa uang, $6 \%$ berupa buah pikir, dan $15 \%$ warga tidak berpartisipasi (Gambar 2). Bentuk 
partisipasi berupa tenaga pada saat terjadi banjir pada daerah-daerah bantaran sungai adalah warga bekerja sama untuk membuat bendungan di sekitar sungai agar air sungai tidak meluap terus menerus ke arah pemukiman warga, dengan cara meletakkan karung-karung yang berisikan pasir di pinggirpinggir sungai. Warga meletakkan karungkarung berisi pasir untuk menghalangi air masuk ke dalam rumah di depan rumahnya. Warga yang rumahnya tidak tenggelam, saling menolong warga yang rumahnya tenggelam dengan cara menyelamatkan barang-barang berharga dan berbagi tempat tinggal.

Bentuk partisipasi berupa uang digunakan untuk warga yang rumahnya masih tenggelam, sehingga belum bisa ditinggali. Biasanya warga akan ditampung di balai desa masing-masing atau tinggal di rumah saudaranya yang tidak terkena banjir.

Bentuk partisipasi berupa buah pikir pada saat terjadi banjir hanya sebesar 6\%, warga terfokuskan dengan korban-korban banjir, kerusakan-kerusakan yang ditimbulkan, dan mengkhawatirkan kondisi tempat tinggalnya sendiri. Bentuk partisipasi berupa buah pikir pada saat terjadi banjir yaitu memprakarsai membendung sungai dengan karung yang berisikan pasir dan menutup sebagian jalan dikarenakan khawatir semakin banyaknya volume air yang masuk serta kendaraan yang mogok saat melewati banjir.

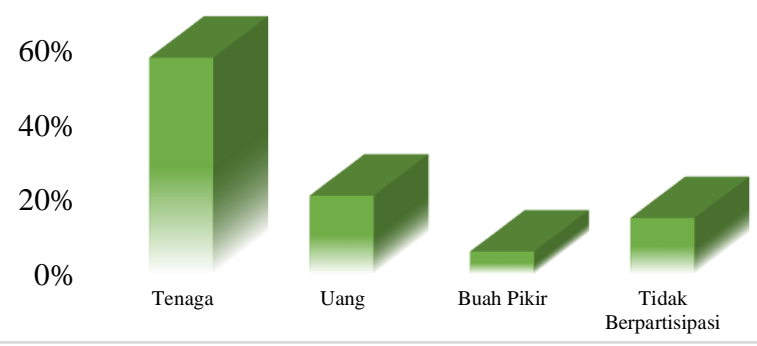

\section{Gambar 2 Diagram Bentuk Partisipasi Masyarakat Saat Terjadi Banjir di Kecamatan Waru tahun 2018}

Bentuk partisipasi masyarakat setelah terjadi banjir (Gambar 3) yaitu $40 \%$ warga berpatisipasi dalam bentuk tenaga, $30 \%$ berbentuk uang, $10 \%$ buah pikir, dan $20 \%$ warga tidak berpartisipasi. $80 \%$ warga turut berpasrtisipasi, jadi tingkat kesadaran masyarakat akan adanya banjir masih tinggi walaupun $20 \%$ warga tidak berpartisipasi. Berdasarkan hasil wawancara, penyebab utama banjir disebabkan karena perilaku masyarakat yang kurang menjaga kebersihan lingkungan, sungai, serta bangunan-bangunan liar di sempadan sungai. Pasca banjir masyarakat berlomba-lomba untuk menjaga wilayahnya agar tidak terdampak banjir. Desa Kepuh Kiriman, dimana wilayah bantaran sungainya telah dijaga oleh polisi sungai, sehingga apabila ada warga yang membuang sampah di sungai akan langsung dikenakan denda sebesar Rp 500.000,-. Desa Wedoro berinovasi dengan mengganti pinggian pembatas jembatan dimana pembatas jembatan yang semula pendek, kini diganti menjadi jaring-jaring besi yang menjulang tinggi dan menanam beberapa tanaman di bantaran sungai, sehingga warga tidak bisa membuang sampah ke sungai.

Masyarakat Desa Waru, Desa Kureksari, Desa Kedungrejo, Desa Medaeng dan Desa Bungurasih kini semakin ketat mengendalikan bangunan-bangunan liar di sempadan sungai. Desa Tambak Rejo kini menjadikan sungai sebagai rumah mereka pula yang harus dijaga, rumah-rumah menghadap ke sungai dan antara rumah dengan sungai diberi ruang yaitu jalan lingkungan dengan lebar 4 meter. Kepedulian masyarakat Desa Berbek untuk menjaga sungai kurang, Sungai Buntung yang melewati Desa Berbek tetap dibiarkan terbuka tanpa diberi pembatas atau diberi tanaman sehingga masih banyak warga yang membuang sampah ke sungai melalui Desa Berbek. 


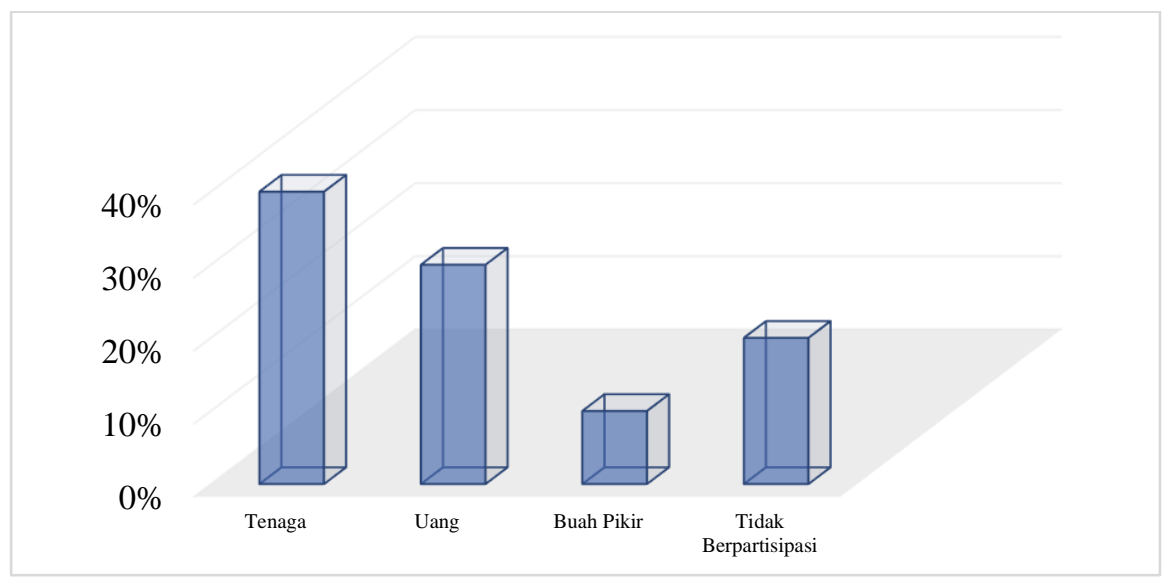

Gambar 3 Diagram Bentuk Partisipasi Masyarakat Setelah Terjadi Banjir di Kecamatan Waru tahun 2018
B. Identifikasi Tingkat Partisipasi di Kecamatan Waru berdasarkan indikator dari Masyarakat UNESCO dalam buku "Petunjuk Praktis Hasil analisis tingkat partisipasi Partisipasi Masyarakat" Tahun 2008 masyarakat pada desa-desa terdampak banjir dijabarkan pada Gambar 4 dan Tabel 4.

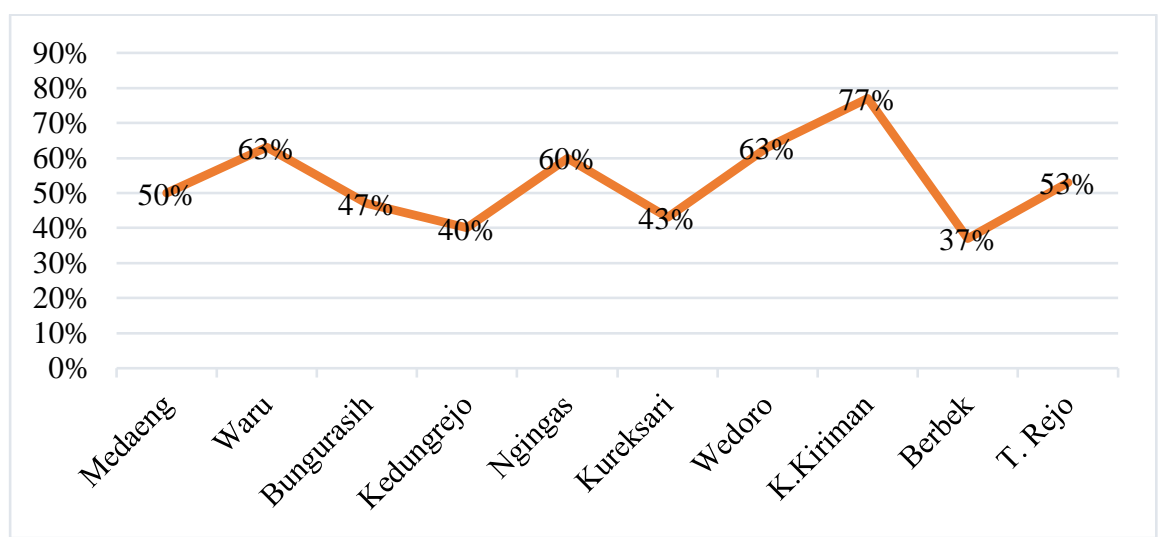

Gambar 4 Tingkat Partisipasi Masyarakat Desa Terdampak Banjir Di Kecamatan Waru 
Tabel 4 Hasil Analisis Skoring Tingkat Partisipasi Masyarakat 10 Desa di Kecamatan Waru Tahun 2018

\begin{tabular}{|c|c|c|c|c|c|c|c|c|c|c|c|}
\hline No & Indikator & Medaeng & Waru & Bungurasih & Kedungrejo & Ngingas & Kureksari & Wedoro & Kepuh Kiriman & Berbek & $\begin{array}{c}\text { Tambak } \\
\text { Rejo }\end{array}$ \\
\hline 1 & Membuat pertemuan & 1 & 1 & 1 & 1 & 1 & 1 & 1 & 3 & 1 & 1 \\
\hline 2 & Pemberdayaan masyarakat & 1 & 1 & 1 & 1 & 1 & 1 & 1 & 3 & 1 & 1 \\
\hline 3 & $\begin{array}{l}\text { Meningkatkan kesadaran } \\
\text { masyarakat }\end{array}$ & 3 & 5 & 3 & 3 & 3 & 3 & 5 & 5 & 3 & 3 \\
\hline 4 & $\begin{array}{l}\text { Promosi keterlibatan } \\
\text { masyarakat }\end{array}$ & 1 & 5 & 3 & 1 & 5 & 1 & 5 & 3 & 1 & 3 \\
\hline 5 & $\begin{array}{l}\text { Membentuk sistem peringatan } \\
\text { dini }\end{array}$ & 1 & 1 & 1 & 1 & 1 & 1 & 1 & 3 & 1 & 1 \\
\hline 6 & $\begin{array}{l}\text { Membangun pengetahuan } \\
\text { masyarakat }\end{array}$ & 1 & 1 & 1 & 1 & 1 & 1 & 1 & 3 & 1 & 1 \\
\hline 7 & Badan koordinasi yang baik & 5 & 5 & 1 & 1 & 5 & 5 & 5 & 5 & 3 & 5 \\
\hline 8 & Melindungi daerah pemukiman & 3 & 3 & 3 & 3 & 5 & 3 & 5 & 5 & 3 & 3 \\
\hline 9 & $\begin{array}{l}\text { Analisis kerusakan dan } \\
\text { kebutuhan }\end{array}$ & 3 & 5 & 3 & 3 & 5 & 3 & 5 & 5 & 3 & 5 \\
\hline 10 & $\begin{array}{l}\text { Pembangunan gedung dan } \\
\text { infrastruktur }\end{array}$ & 5 & 5 & 5 & 3 & 5 & 5 & 5 & 5 & 3 & 5 \\
\hline 11 & Kerjasama dengan media massa & 1 & 1 & 1 & 1 & 1 & 1 & 1 & 3 & 1 & 1 \\
\hline 12 & Kajian pasca bencana & 5 & 5 & 5 & 5 & 3 & 1 & 3 & 3 & 1 & 3 \\
\hline & TOTAL & 30 & 38 & 28 & 24 & 36 & 26 & 38 & 46 & 22 & 32 \\
\hline & PERSENTASE & $50 \%$ & $63 \%$ & $47 \%$ & $40 \%$ & $60 \%$ & $43 \%$ & $63 \%$ & $77 \%$ & $37 \%$ & $53 \%$ \\
\hline & KRITERIA & Consultasion & Partnership & Consultasion & Consultasion & Placation & Consultasion & Partnership & Delegated power & Informing & Placation \\
\hline
\end{tabular}

Sumber : Hasil Analisis Tahun 2018 
Desa Berbek berada pada tangga Informing, yaitu merupakan transisi antara non participation dengan tokenism. Desa Kedungrejo, Kureksari, Bungurasih, dan Medaeng berada pada tingkat consultation, pada tingkatan ini pemerintah memberi informasi dan mengundang opini masyarakat. Desa Tambak Rejo dan Ngingas berada pada tingkat placation, pada tingkatan ini masyarakat sudah mulai mempunyai pengaruh terhadap program pemerintah, ini terbukti sudah adanya keterlibatan masyarakat yang ikut menjadi anggota komite (badan kerjasama) yang terdiri dari wakil-wakil dari instansi pemerintah. Desa Waru dan Wedoro berada pada tingkat partisipasi tinggi, yaitu partnership, pada tingkatan ini masyarakat memiliki kekuatan bernegosiasi dengan pemegang kekuasaan. Desa Kepuh Kiriman merupakan desa dengan tingkat partisipasi masyarakat paling tinggi di Kecamatan Waru yaitu berada pada tingkat delegated power. Masyarakat pada tingkat ini, diberi limpahan kekuasaan untuk membuat keputusan pada rencana atau program-progam pembangunan yang bermanfaat bagi mereka. Untuk memecahkan permasalahan yang ada, pemerintah harus mengadakan tawar menawar dibandingkan dengan memberi tekanan kepada masyarakat.

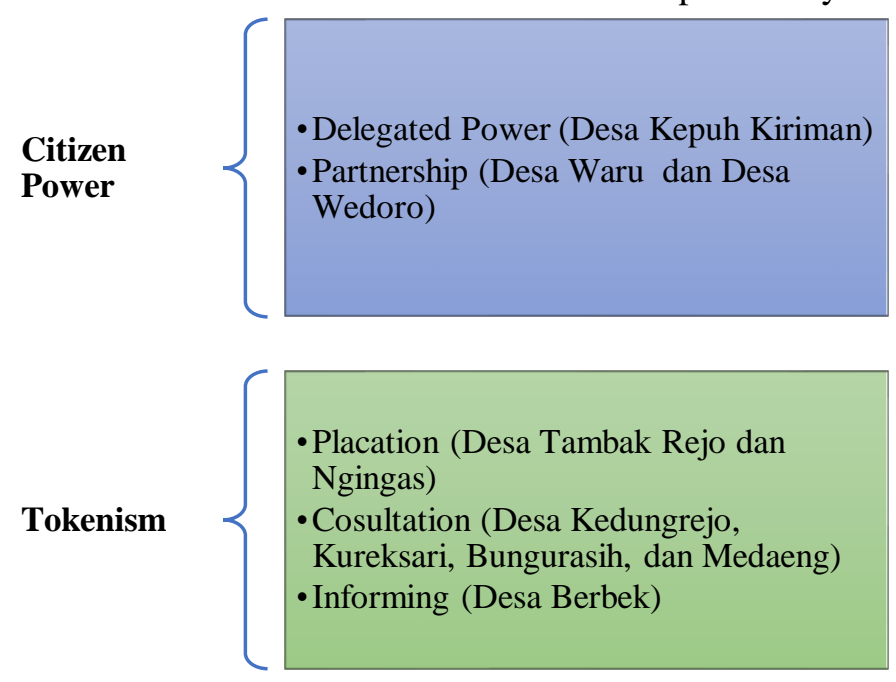

\section{Gambar 5 Tangga Tingkat Partisipasi Masyarakat Desa Terdampak Banjir Di Kecamatan Waru}

Berdasarkan Gambar 5, Partnership dan Delegated power merupakan tingkatan yang masuk dalam citizen power (publik berdaya). Saat partisipasi publik telah mencapai citizen power, maka otoritas yang berkuasa sedang benar-benar mendahulukan peran serta publik dalam berbagai hal. Tokenism (delusif) yang memiliki rentang dari informing, consultation, and placation.
Kategori tokenism, otoritas yang berkuasa menciptakan citra, tidak lagi menghalangi partisipasi publik. Kenyataannya berbeda, benar partisipasi masyarakat dibiarkan, namun mereka mengabaikannya. Mereka tetap mengeksekusi rencanya semula. Persebaran tingkat partisipasi masyarakat Kecamatan Waru dalam mitigasi bencana bancir dijabarkan pada Gambar 6. 


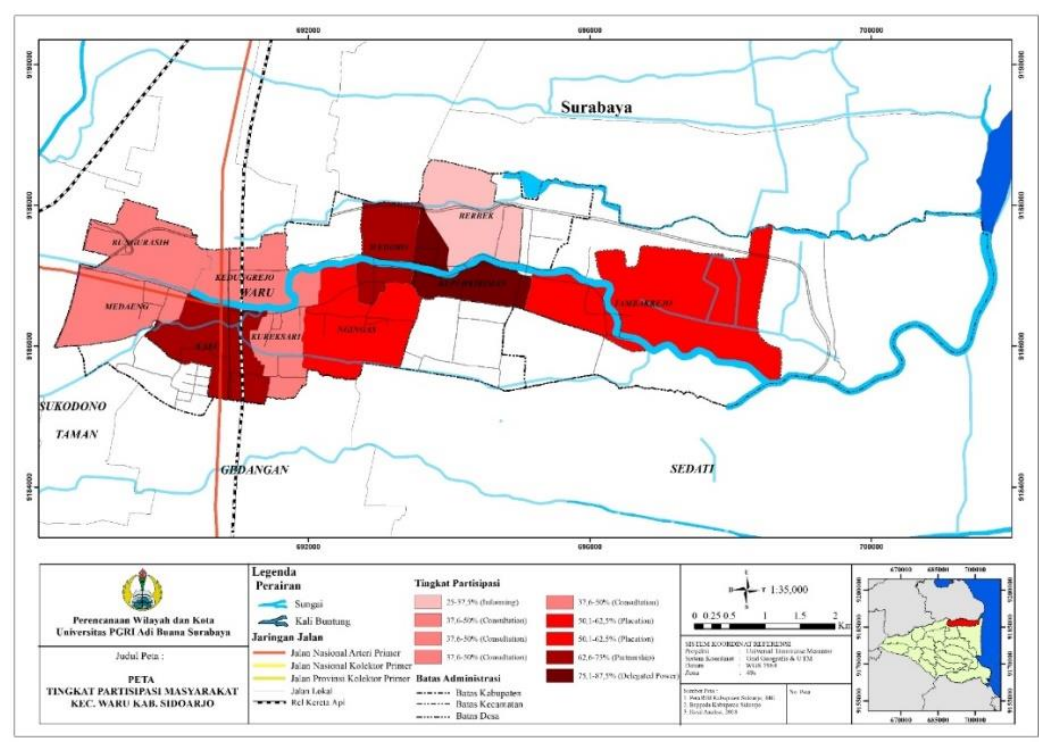

\section{Gambar 6 Peta Tingkat Partisipasi Masyarakat Desa Terdampak Banjir Di Kecamatan Waru}

\section{KESIMPULAN}

Berdasarkan hasil analisis maka diperoleh beberapa kesimpulan bahwa bentuk partisipasi masyarakat di Kecamatan Waru terhadap penanggulangan banjir Sungai Buntung pada tahapan sebelum banjir, saat banjir, dan sesudah banjir terbesar berupa tenaga. Bentuk partispasi tenaga pada tahapan sebelum banjir sebesar $41 \%$, pada tahapan saat terjadi banjir 58\% dan pada tahapan setelah banjir sebesar $40 \%$. Tingkat partisipasi masyarakat di Kecamatan Waru dalam menanggulangi banjir Sungai Buntung menurut tangga partisipasi Armstein (1969) berdasarkan analisis skoring terdiri dari Desa Berbek berada pada tangga ketiga yaitu tingkat informing atau pemberian informasi, Desa Kedungrejo, Desa Kureksari, Desa Bungurasih dan Desa Medaeng berada pada tingkat consultation atau konsultasi. Desa Tambak Rejo dan Ngingas berada tingkat placation atau perujukan. Desa Waru dan Desa Wedoro berada pada tingkat partisipasi partnership atau kerja sama dan Desa Kepuh Kiriman pada tingkat delegated power atau pelimpahan kekuasaan.

\section{DAFTAR PUSTAKA}

Ali, M. 2010. Metodologi dan Aplikasi Riset Pendidikan. Bandung: Pustaka Cendekia Utama.

Anonim 2009. Peraturan Daerah Kabupaten Sidoarjo No 06 Tahun 2009 Tentang Rencana Tata Ruang Wilayah Kabupaten Sidoarjo. Pemerintah Kabupaten Sidoarjo.

Deviyanti, D. 2013. Studi Partisipasi Masyarakat Dalam Pembangunan Di Kelurahan Karangjati Kecamatan Balikpapan. Ejournal Administrasi Negara. Volume 1 Nomor 2. From http:// ejournal.an.fisipunmul.org.

Isbandi, R.A. 2007. Perencanaan Partisipatoris Berbasis Asset Komunitas: Dari Pemikiran Menuju Penerapan. Depok: FISIP UI Press.

Iswara, R. Astuti, W. \& Putri, R. A. 2017. Kesesuaian Fungsi Taman Kota Dalam Mendukung Konsep Kota Layak Huni di Surakarta. Jurnal Ilmiah Arsitektur dan Lingkungan Binaan Vol. 15. No. 1. https://jurnal.uns.ac.id/Arsitektura/article/view/11406.

Noorwandy, A. Resmawan, E. \& Rande, S. 2017. Partisipasi Masyarakat Dalam Penanggulangan Masalah Banjir Di Kelurahan Sempaja Barat Kecamatan Samarinda Utara. eJournal Administrative Reform. $\quad$ http://ar.mian.fisip-unmul.ac.id/site/wpcontent/uploads/2018/02/eJournal\%20Administrative\%20Reform\%20Aries\%20Noorwandy\% 20FIX\%20(02-27-18-04-31-55).pdf.

Riska, N. \& Yuliastuti, N. 2013. Bentuk Adaptasi Masyarakat Terhadap Banjir Di Kampung Purwadinatan dan Jurnatan Kota Semarang. eJournal-PWK UNDIP Vol. 2 No. 3. https://ejournal3.undip.ac.id/index.php/pwk/article/view/2875. 
Undang-Undang No 24 Tahun 2007 Tentang Penanggulangan Bencana.

UNESCO. 2008. Petunjuk Praktis Partisipasi Masyarakat dalam Penanggulangan Banjir. Jakarta.

Satries, W. I. 2011. Mengukur Tingkat Partisipasi Masyarakat Kota Bekasi Dalam Penyusunan APBD Melalui Pelaksanaan Musrenbang 2010. Jurnal Kybernan Vol. 2 No. 2.

Umeidini, F, Nuriah, E \& Fedryansyah, M. 2019. Partisipasi Masyarakat Dalam Penanggulangan Bencana di Desa Mekargalih Kecamatan Jatinangor. Jurnal Pekerjaan Sosial Vol. 2 No. 1. http://jurnal.unpad.ac.id/focus/article/view/23115.

Utami, D. F. 2013. Partisipasi Masyarakat Dalam Mitigasi Bencana Banjir Di Kelurahan Sangkrah, Kecamatan Pasar Kliwon Surakarta. http://eprints.ums.ac.id/29087/9/02._Artikel_Publikasi_Ilmiah.pdf.

Wesli. 2011. Kajian Spasial Dan Partisipasi Masyarakat Sebagai Upaya Pengendalian Banjir Di Kabupaten Aceh Utara. Teras Jurnal Vol. 1 No. 1. http://teras.unimal.ac.id/index.php/teras/article/download/58/55.

Widayanti, S. Y. M. 2016. Sikap Sosial dan Partisipasi Masyarakat dalam Penanggulangan Bencana Alam Banjir. https://ejournal.kemsos.go.id/index.php/jpks/article/download/1353/760. 